\title{
Description of a new species of cecidomyiid (Diptera: Cecidomyiidae) predator of mealybugs (Hemiptera: Pseudococcidae) on sugarcane
}

\author{
Maria Virgínia Urso-Guimarães ${ }^{1}$; Maiara Alexandre $\mathrm{Cruz}^{2,3}$; Nilza Maria Martinellii, ${ }^{2,4}$ \& Ana Lúcia Gonzalez Benfatti Peronti ${ }^{2,5}$ \\ 1 Universidade Federal de São Carlos (UFSCAR), Centro de Ciências Humanas e Biológicas (CCHB), Departamento de Biologia (DBI0), \\ Laboratório de Sistemática de Diptera. Sorocaba, SP, Brasil. ORCID: http://orcid.org/0000-0003-3657-9379. E-mail: mvirginiaurso@gmail.com \\ 2 Universidade Estadual Paulista "Júlio de Mesquita Filho" (UNESP), Faculdade de Ciências Agrárias e Veterinárias (FCAV), \\ Departamento de Fitossanidade, Laboratório de Biossistemática de Hemiptera. Jaboticabal, SP, Brasil. \\ 3 ORCID: http://orcid.org/0000-0003-2892-7038. E-mail: maiara_agronomia@hotmail.com \\ ${ }^{4}$ ORCID: http://orcid.org/0000-0003-3201-9120. E-mail: nilza.martinelli@unesp.br \\ ${ }^{5}$ ORCID: http://orcid.org/0000-0003-1788-0342. E-mail: anaperonti@gmail.com
}

\begin{abstract}
Diadiplosis saccharum sp. nov. (Diptera: Cecidomyiidae) is described based on male and female prey on nymphs of mealybug Saccharicoccus sacchari (Cockerell) (Hemiptera: Pseudococcidae) on Saccharum spp. (Poaceae) in São Paulo State, Brazil. Herein, the genus is composed by 33 species. The key of the eight species of the Diadiplosis distributed in Brazil is updated.
\end{abstract}

Key-Words. Biodiversity; Ecological association; Neotropical region; Predaceous insect; Taxonomy.

\section{INTRODUCTION}

Diadiplosis Felt (Diptera: Cecidomyiidae) is a cosmopolitan genus, better distributed in the tropical regions of the world, once thirteen of the 32 described species are distributed in Neotropical region (Gagné \& Jaschhof, 2017). Larvae of these cecidomyiids are predators of several species of scale insects, especially mealybugs (Hemiptera: Pseudococcidae), and whiteflies (Hemiptera: Aleyrodidae) of which many are pests of crops of agricultural importance.

In Brazil seven species of Diadiplosis were reported, all predator of scale insects of the families Coccidae, Ericoccidae, Monophlebidae and Pseudococcidae. Diadiplosis coccidivora Felt, D. multifila (Felt) and D. pseudococci Felt have a wider distribution, chiefly in the Neotropical region. The other four species were registered only to the State of Espírito Santo, Brazil: Diadiplosis abacaxii Culik \& Ventura associated with Dysmicoccus brevipes (Cockerell, 1893) (Pseudococcidae) on pineapple, Ananas comosus (L.) Merr. (Bromeliaceae) (Culik \& Ventura, 2013a); Diadiplosis bellingeri Culik \& Ventura with species of undetermined pseudococcid and the coccid Saissetia cf. coffeae obtained from coffee, Coffea arabica L. (Rubiaceae); Diadiplosis jamboi Culik \& Ventura, with Planococcus halli Ezzat and McConnell (Pseudococcidae) on jambo fruit, Syzygium jam- bos (L.) Alston (Myrtaceae), and Diadiplosis martinsensis Culik \& Ventura, with Pseudococcus cf. jackbeardsleyi Gimpel and Miller (Pseudococcidae) on pineapple and coffee (Culik \& Ventura, 2013b).

The genus Diadiplosis belongs to the supertribe Cecidomyiidi by possess 12 antennal flagellomeres, but this genus is unplaced to tribe. Other systematic studies need to be carried out to clarify the relationship among the genus of this supertribe. Diadiplosis is characterized by the eyes separated laterally or facets very sparse there; facets usually hexagonal above and below, circular and farther apart laterally; tarsal claws curved at the basal third; tarsal claws toothed or simple; presence of strap like adult abdominal sclerites; female tergite 10 with a pair of strong setae, with or without lesser ones; female cerci ovoid and without differentiated apical sensorial setae; gonocoxites may have ventro-apical lobes; gonostylus variously shaped, completely setulose, tooth pectinate; hypoproct entire to deeply bilobed (Gagné, 1994, 2010).

The systematic and biology of the cecidomyiid predators on the World Coccomorpha was made by Harris $(1968,1997)$, followed by taxonomic changes to Nearctic (Gagné, 1973) and Neotropical fauna (Gagné, 1994). Since then, little new information has become available, and four species have been described for the genus in the Neotropical region (Culik \& Ventura, 2012, 2013a, 2013b). 
In this paper, a new species named Diadiplosis saccharum sp. nov. is described based on male and female specimens reared from nymphs of Saccharicoccus sacchari Cockerell) (Hemiptera: Pseudococcidae) in São Paulo State sampled on Saccharum spp. (Poales: Poaceae). An identification key to males of Diadiplosis distributed in Brazil is updated.

\section{MATERIAL AND METHODS}

Sampling of the natural enemies, among them the new species of Diadiplosis, collected from sugarcane stem (Saccharum spp.) prey on mealybugs (Saccharicoccus sacchari) between August 2016 and August 2017. Infested nodes were inspected visually mainly in looking for immature predators in Jaboticabal

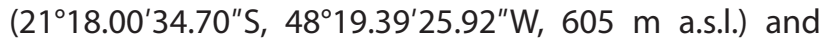

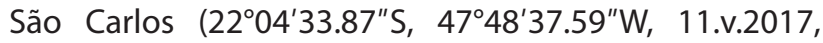
$856 \mathrm{~m}$ a.s.l.), both in State of São Paulo, Brazil. From 10 to 20 individuals of $S$. sacchari per sample were transferred to plastic tubes for rearing its natural enemies in BOD for 28 days. The adults of cecidomyiids were obtained in this process. They were preserved in $80 \%$ ethanol and later were mounted on permanent slides using the methodology outlined by Gagné (1994) and deposited in Museu de Zoologla da Universidade de São Paulo. Topotypes of cf., Diadiplosis abacaxii (2 $\sigma^{7}$ and 6 \%), cf., D. bellingeri (1 $\sigma^{7}$
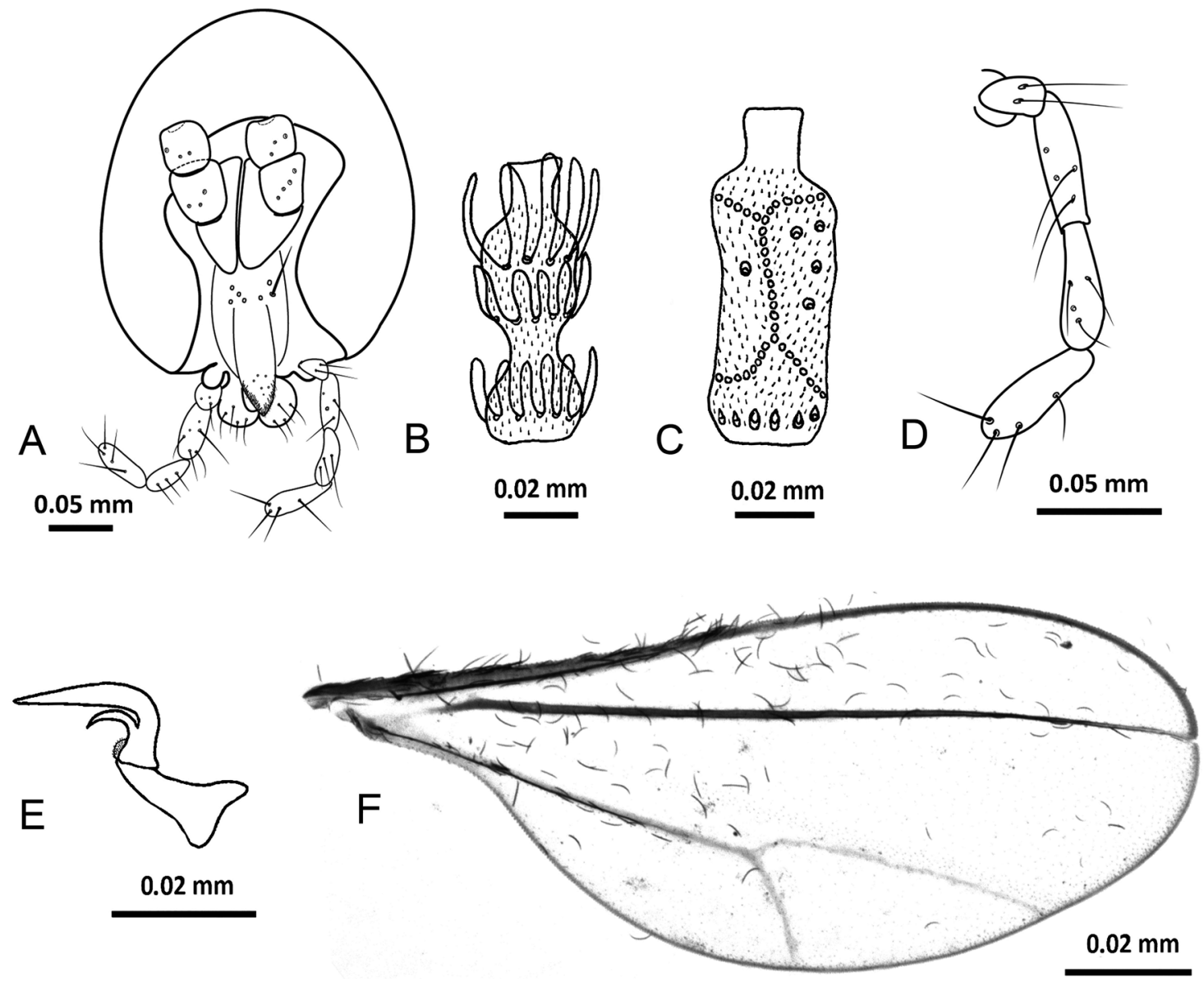

Figure 1. Diadiplosis saccharum sp. nov. (A) Male head, frontal view, (B) Male flagellomere 3; (C) Female flagellomere 3; (D) Maxillary palp four-segmented; (E) Tarsal claw, leg 3; (F) Wing. and 1 \%) and $c f$., D. jamboi (3 \%) from Instituto Capixaba de Pesquisa, Assistência Técnica e Extensão Rural (INCAPER) were examined. The specimens of $D$. martinsensis and the male of $D$. jamboi were not available for examinawith original description from literature. The larvae of cecidomyiids obtained among the sorted biological material was totally directed to obtain adults, by the small number of specimens. The areas where the larvae were found are more shaded and moist fields, which could be limiting for insects as small and with fragile bodies as the dipter in question. Furthermore, in sugarcane fields, even though scale insects are frequent, there is a constant application of insecticides to control various pest insects, which negatively end up interfering in beneficial insects as natural enemies.

\section{RESULTS}

\section{Taxonomy}

\section{Genus Diadiplosis Felt, 1911}

Type species: Diadiplosis cocci Felt (orig. des.).

For the diagnosis of Diadiplosis see Gagné (1994) and Gagné (2010).
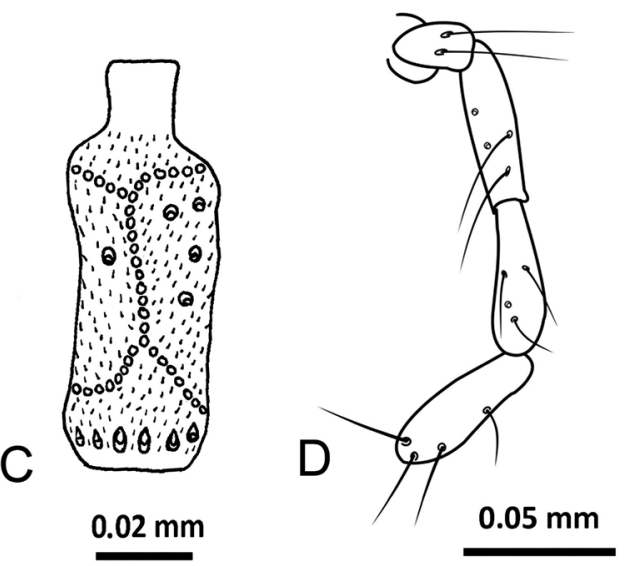
tion, and in this way, their characteristics were compared 

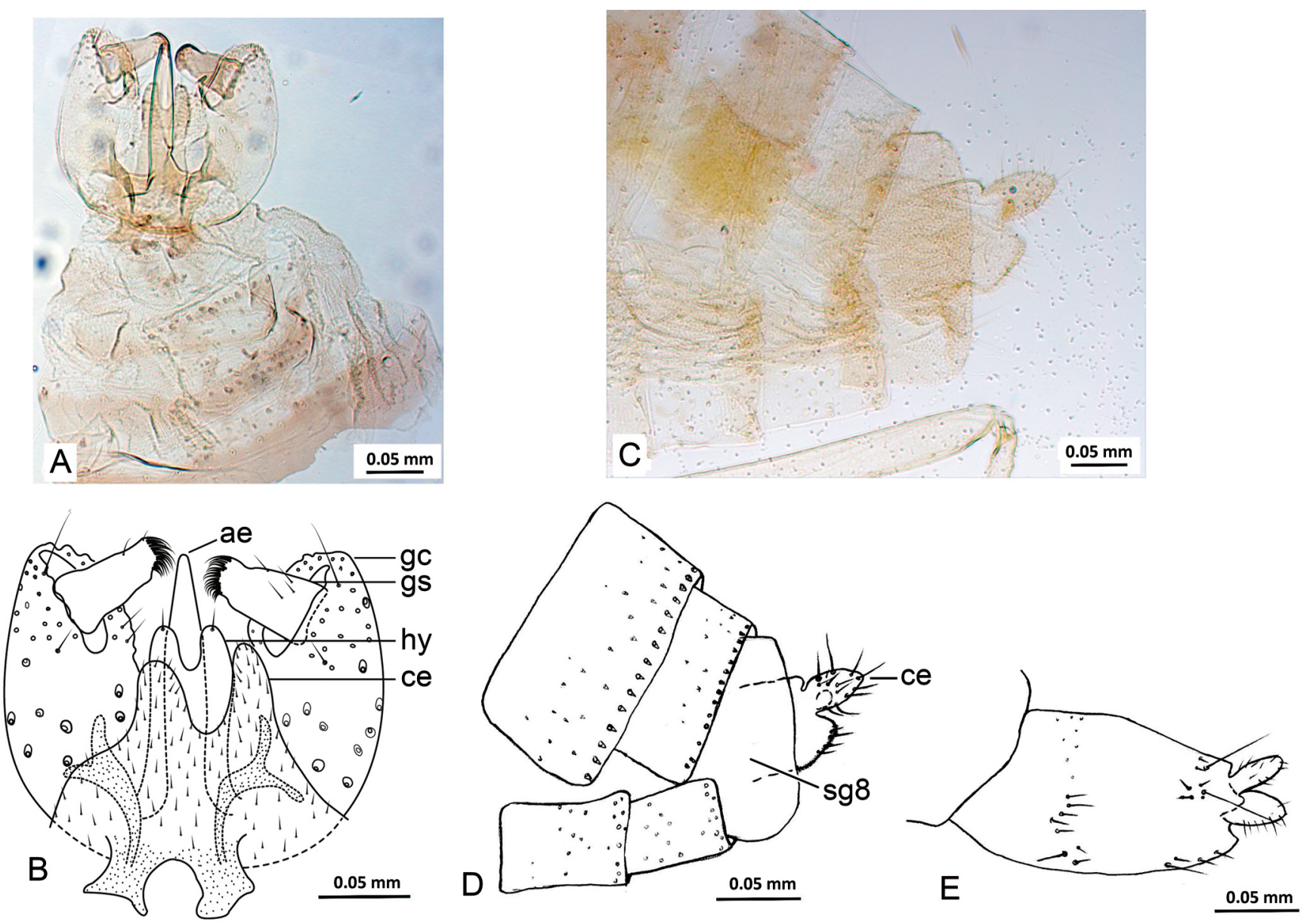

Figure 2. Diadiplosis saccharum sp. nov. (A) Male terminalia and posterior abdominal segments, vview; (B) Detailed male terminalia, dorsal view; (C) Female post-abdomen; (D) Female abdomen detailed. Abbreviations: $\mathrm{de}=$ aedeagus, $\mathrm{ce}=$ cercus, $\mathrm{gc}=$ gonocoxites, gs $=$ gonostylus, hy $=$ hypoproct, $\mathrm{sg} 8=$ segment 8 .

\section{Diadiplosis saccharum sp. nov. Urso-Guimarães (Figs. 1-3)}

Description: Adult (Figs. 1-2): Body length: male, 1.49-1.65 mm ( $=2)$; female, $1.04-1.89 \mathrm{~mm}(\mathrm{~N}=2)$. Head (Fig. 1A): Antennae with scape obconic, 5-6 setae, pedicel globose 3-4 setae. Antennal length: male 0.9-1.05 mm ( $=2)$, and female, 0.9-0.95 $\mathrm{mm}(\mathrm{N}=2)$. Male flagellomeres binodal, circumfila with three loops similar in length (Fig. 1B). Male flagellomere 3 length 0.08-0.09 mm; internode length $0.01 \mathrm{~mm}$, width 0.012; neck length $0.016-0.017 \mathrm{~mm}$, width $0.013 \mathrm{~mm}(\mathrm{~N}=2)$. Female flagellomeres cylindrical, circumfila as in Fig. 1C, flagellomere 3 length $1.0 \mathrm{~mm}$; neck length $0.018 \mathrm{~mm}$, width $0.2 \mathrm{~mm}(\mathrm{~N}=2)$. Flagellomeres 1 and 2 not connate. Male and female flagellomere 12 with a short apical process. Frontoclypeus with approximately 15 setae $(\mathrm{N}=4)$. Labrum long and tapering, with two pairs of ventral setae. Hypopharynx shape similar to labrum, with long, anteriorly directed lateral setulae. Labella round, convex, each with three lateral setae and one mesal setae. Palpus four-segmented, the first globose and the other three cylindrical; second and third segments with equal length, the fourth 1.5 longer than second and third; all setose (Fig. 1D). Thorax: Scutum dark brown with a row of dorsocentral and lateral setae, scutellum light brown with scattered setae, anepimeron setose, other pleural sclerites asetose. Legs: Tarsal claws with a small tooth in all legs, empodium rudimentary (Fig. 1E). Wing: Wing length: $0.15 \mathrm{~mm}$ in male; $0.17 \mathrm{~mm}$ in female $(n=2) ; R 1$ joining $C$ at about wing midlength, CuA forked. (Fig. 1F).

Abdomen: Male (Fig. 2A): tergites 1-7 rectangular with a complete row of caudal setae, some lateral setae, two basal trichoid sensillae, and scattered scales. Tergite 8 unsclerotized with a row of caudal setae, trichoid sensillae and scales absent. Sternites 2-7 strap like sclerites with setae more abundant mesally, a complete row of caudal setae, some lateral setae and 2 basal trichoid sensilla, and scattered scales. Sternite 8 less sclerotized than preceding sclerites, setae, trichoid sensilla, and scales absent. Female (Fig. 2C): tergites and sternites as in male, except for tergites and sternites 1-7 wider than in male and tergite and sternite 8 unsclerotized with a row of setae each, trichoid sensillae and scales absent. Male terminalia (Fig. 2B): gonocoxites oblong, with dorso-lateral distal margin surpassing the insertion of gonostylus, setae concentrated at apex; gonostylus rectangular, stout, length 0.056-0.061 mm, width 0.024-0.027 $\mathrm{mm}(\mathrm{N}=2)$, with scattered setae, and setulae covering all gonostylus; aedeagus very long (1.2 times longer than hypoproct and 1.7 times longer than cercus); hypoproct bilobed, round, with a single long seta on each lobe and a row of setae 
longitudinally in each lobe; cercus fused at base, deeply bilobed, round, covered by setae. Ovipositor: tergite 10 with a pair of long and strong setae, with lesser ones; cerci elongate-ovoid as shown in Fig. 2D-2E $0.15 \mathrm{~mm}$ long $(\mathrm{N}=2)$.

Holotype: Male: BRAZIL, São Paulo: Jaboticabal (21⒙00'34.70"S, 48¹9.39'25.92"W, $605 \mathrm{~m})$, col. 10.iv.2017, Cruz, M.A. col., Urso-Guimarães, M.V. det. Slide mounted deposited in MZSP. Paratypes: Same data of holotype, except for: $8 \sigma^{x} ; 4$ \%, Cruz, M.A. col., Urso-Guimarães, M.V. det.; 1 specimen, BRAZIL, State

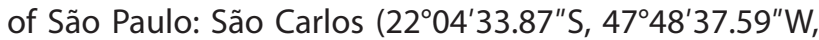
11.v.2017, 856 m a.s.I.), Cruz, M.A. col., Urso-Guimarães, M.V. det. Slide mounted deposited in MZSP.

Etymology: The name saccharum is based on the name of the sugarcane genus (Saccharum), cultivar in which the specimens of the new species was found prey on nymphs of Saccharicoccus sacchari.

Biology: Adults of Diadiplosis saccharum sp. nov. were reared from leaf sheaths on stem nodes of sugarcane (Saccharum spp.) with larvae of cecidomyiids preying on nymphs of of Saccharicoccus sacchari (Fig. 3), which is a potential pest for Poaceae plant species, since sugarcane producers have reported frequent infestations in Brazil (Cruz et al., 2019).

Remarks: Despite the new species resemble the Neotropical Diadiplosis, D. bellingeri, D. martinsensis and
D. aleyrodici (Felt, 1922), with the eyes undivided, palp 4-segmented, tarsal claws toothed at base or not (except in D. martinsensis), cercus and hypoproct bilobed, Diadiplosis saccharum sp. nov. differ from all known species based mainly on the combination of the characters of male terminalia (Fig. 2B): gonocoxite oblong with the dorso-lateral distal margin surpassing the insertion of gonostyli, gonostylus rectangular and stout. The new species and $D$. pseudococci have prolongation of the dorso-lateral distal margin of gonocoxite after the insertion of gonostyle, but in this species, the prolongation is larger and shorter than in D. pseudococci (Fig. 4E). A long and triangular aedeagus is shared with $D$. bellingeri and $D$. martinsensis, but in the first, the hypoproct is deeper bilobed (Fig. 4G) than in the new species, and in the latter the aedeagus is smaller than hypoproct and cercus (Fig. 4F). The male terminalia of $D$. saccharum resembles the general shape of the $D$. abacaxii terminalia by the sclerotization, but they differ greatly in aedeagus, bulbous in D. abacaxii and regular in D. saccharum. In addition, they also differ in the number of segments of palpi, three in D. abacaxii and four in D. saccharum.

This is the first register of a cecidomyiid larvae preying on an insect pest on Saccharum spp. (Poaceae) - a major agricultural commodity in the tropics and used mainly for making sugar and ethanol for fuel. Saccharicoccus sacchari can be classified as an emergent pest in Brazil, since sugarcane producers have reported infestations frequently (Cruz et al., 2019). Further studies can indicate if the cecidomyiid can be used in biological control of S. sacchari in sugarcane plantation.
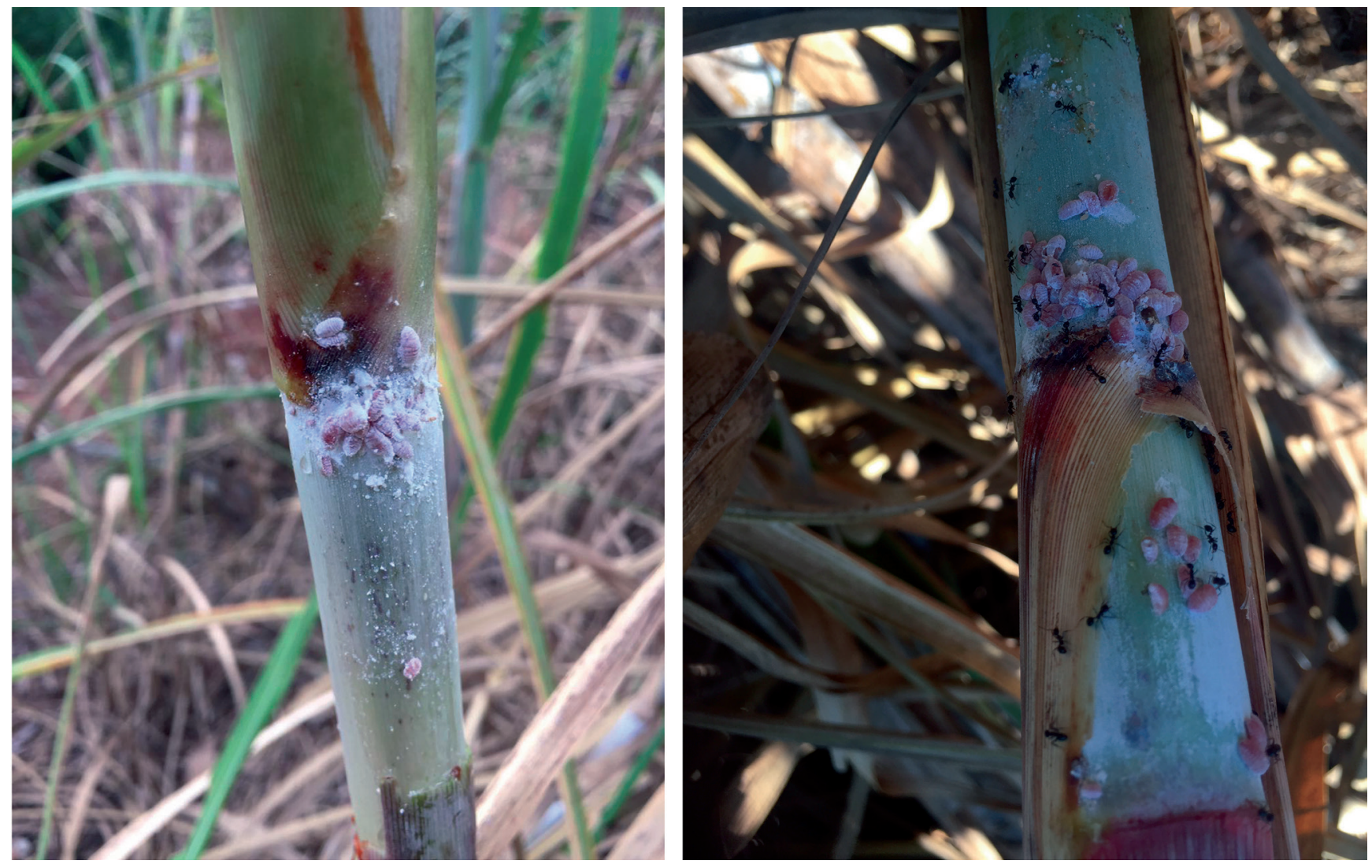

Figure 3. Stem nodes of sugarcane Saccharum spp. infested with nymphs of mealybugs Saccharicoccus sacchari. 


\section{Key to adult males of Diadiplosis distributed in Brazil (Modified of Culik \& Ventura, 2013b)}

1. Maxillary palp 3-segmented, aedeagus cylindrical

1.' Maxillary palp 4-segmented, aedeagus triangular 4

2. Aedeagus longer than cercus and hypoproct, aedeagus bulbous (Fig. 4A) Diadiplosis abacaxii Culik \& Ventura

2. Aedeagus approximately equal in length to hypoproct, aedeagus not bulbous (Fig. 4B)

3. Cercus, hypoproct and aedeagus equal in length, hypoproct shallowly bilobed (Fig. 4B) Diadiplosis multifila Felt

3'. Hypoproct and aedeagus larger and longer than cerci, hypoproct deeply bilobed (Fig. 4C) Diadiplosis jamboi Culik \& Ventura

4. Claws of legs 2 and 3 simple

4'. Claws of legs 2 and 3 dentate .. 6

5. Hypoproct unilobed; aedeagus shorter than hypoproct and cerci, dorso-lateral distal margin of gonocoxite without prolongation (Fig. 4D)

.Diadiplosis coccidivora (Felt)

5. Hypoproct deeply bilobed, aedeagus longer than hypoproct and cerci, dorso-lateral distal margin of gonocoxite with a long and narrow prolongation (Fig. 4E) ...Diadiplosis pseudococci Felt

6. Aedeagus shorter than hypoproct (Fig. 4F). Diadiplosis martinsensis Culik \& Ventura

6. Aedeagus much longer than hypoproct (Fig. 4G) Diadiplosis bellingeri.................

7. Gonostylus clavate and curved, dorso-lateral distal margin of gonocoxite without prolongation (Fig. 4G)

7. Gonostylus rectangular and stout, dorso-lateral distal margin of gonocoxite with prolongation after insertion of gonostyle (Fig. 2B)
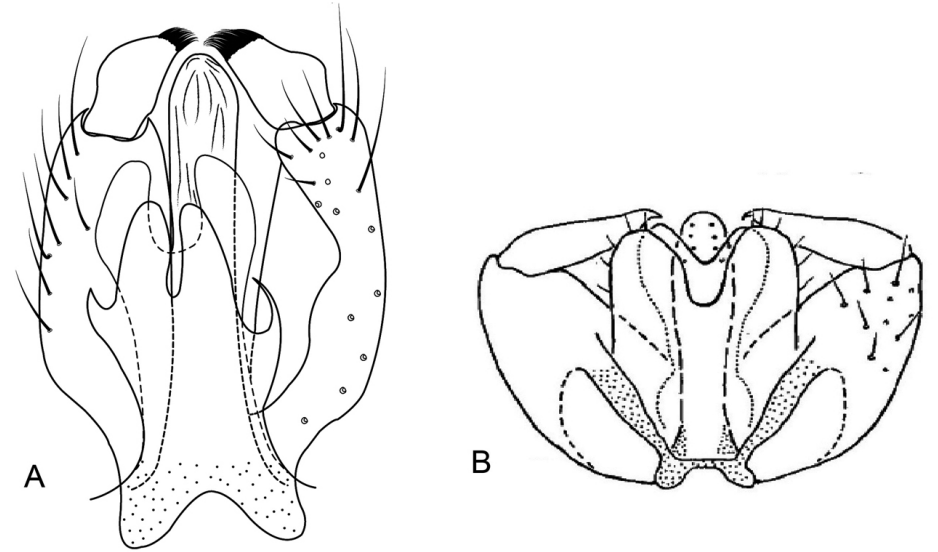

C
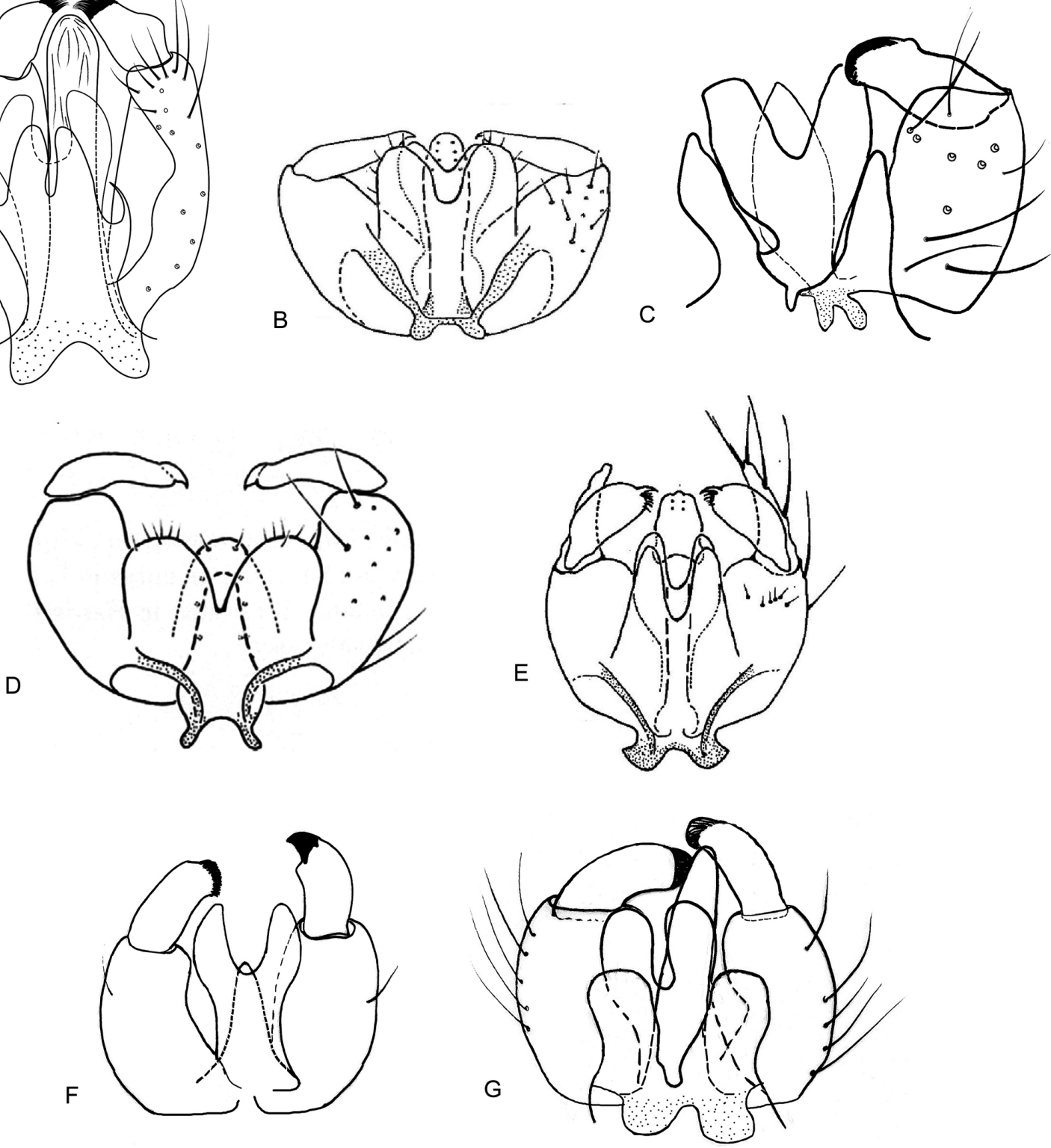

Figure 4. Male terminalia of Diadiplosis species. (A) D. abacaxii, (B) D. multifila, (C) D.jamboi, (D) D. coccidivora, (E) D. pseudococci, (F) D. martinsensis, (G) D. bellingeri. Illustrations B, D and E modified from Harris (1968); and C and F modified from Culik \& Ventura (2013b). 


\section{ACKNOWLEDGEMENTS}

The authors gratefully acknowledge the CAPES (Coordenação de Aperfeiçoamento de Pessoal de Nível Superior) for financial support, Dr. José A. Ventura and Dr. Mark P. Culik (INCAPER) for borrowing the specimens of topotype material of Diadiplosis, Dr. Carlos Lamas (MZUSP) for providing access to the facilities at MZUSP and Dr. Raymond J. Gagné for commenting on a draft version of the manuscript.

\section{REFERENCES}

Cruz, M.A.; Peronti, A.L.B.G.; Martinelli, N.M.; Costa, V.A.; Ignácio, G.P. \& Almeida, L.M. 2019. Complex of Natural Enemies Associated With Scale Insects (Hemiptera: Coccomorpha) on Sugarcane in Brazil. Journal of Agricultural Science, 11(4): 160-175.

Culik, M.P. \& Ventura, J.A. 2012. A new species of cecidomyiid (Diptera, (ecidomyiidae) predator associated with scale insect (Hemiptera, Coccoidea) pests of coffee. Journal of the Entomological Research Society, 14: 9-13.

Culik, M.P. \& Ventura, J.A. 2013a. A new species of cecidomyiid (Diptera, (ecidomyiidae) predator of scale insect (Hemiptera, Coccoidea) pests of pineapple. Acta Phytopathologica et Entomologica Hungarica, 48: 129-134.

Culik, M.P. \& Ventura, J.A. 2013b. Two new neotropical species of Midge (Diptera: Cecidomyiidae) predators of scale insects (Hemiptera: Coccoidea). Journal of the Entomological Research Society, 15(2): 103-111. Gagné, R.J. 1973. A generic synopsis of the Nearctic Cecidomyiidi (Diptera: (ecidomyiidae, (ecidomyiinae). Annals of the Entomological Society of America, 66: 857-889.

Gagné, R.J. 1994. The Gall Midges of the neotropical region. Ithaca, Cornell University Press. 352p.

Gagné, R.J. 2010. Update for a catalog of the Cecidomyiidae (Diptera) of the world. Digital version 1. Washington, USDA. 545p. Available at: http:// www.ars.usda.gov/SP2UserFiles/Place/12754100/Gagne 2010 World Catalog Cecidomyiidae.pdf. Acessed in: 17/11/2019.

Gagné, R.J. \& Jaschhof, M. 2017. A Catalog of the Cecidomyiidae (Diptera) of the World. 4. Ed. 762p. Available at: https://www.ars.usda.gov/ ARSUserFiles/80420580/Gagne 2017 World Cat 4th ed.pdf. Acessed in: 17/11/2019.

Harris, K.M. 1968. A systematic revision and biological review of the cecidomyiid predators (Diptera, Cecidomyiidae) on world Coccoidea. Transactions of the Royal Entomological Society of London, 119: 409-494.

Harris, K.M. 1997. Cecidomyiidae and other Diptera. In: Ben-Dov, Y.; Hodgson, C.J. (Eds.). Soft scale insects - their biology, natural enemies and control, Amsterdam. Elesevier Science. p. 61-68. (World Crop Pests, vol. 7B). 